\title{
Estimating Potential Evaporation from Vegetated Surfaces for Water Management Impact Assessments Using Climate Model Output
}

\author{
VICTORIA A. BELL \\ Centre for Ecology and Hydrology, Crowmarsh Gifford, United Kingdom \\ NiCOLA GEDNEY \\ Met Office Hadley Centre (Reading Unit), University of Reading, Reading, United Kingdom \\ ALISON L. KAY \\ Centre for Ecology and Hydrology, Crowmarsh Gifford, United Kingdom \\ RODERICK N. B. SMITH AND RichARD G. JONES \\ Met Office Hadley Centre (Reading Unit), University of Reading, Reading, United Kingdom \\ ROBERT J. MOORE \\ Centre for Ecology and Hydrology, Crowmarsh Gifford, United Kingdom
}

(Manuscript received 15 September 2010, in final form 7 February 2011)

\begin{abstract}
River basin managers concerned with maintaining water supplies and mitigating flood risk in the face of climate change are taking outputs from climate models and using them in hydrological models for assessment purposes. While precipitation is the main output used, evaporation is attracting increasing attention because of its significance to the water balance of river basins. Climate models provide estimates of actual evaporation that are consistent with their simplified land surface schemes but do not naturally provide the estimates of potential evaporation (PE) commonly required as input to hydrological models. There are clear advantages in using PE estimates controlled by atmospheric forcings when using stand-alone hydrological models with integral soil-moisture accounting schemes. The atmosphere-land decoupling approximation that PE provides can prove to be of further benefit if it is possible to account for the effect of different, or changing, land cover on PE outside of the climate model. The methods explored here estimate Penman-Monteith PE from vegetated surfaces using outputs from climate models that have an embedded land surface scheme. The land surface scheme enables an examination of the dependence of canopy stomatal resistance on atmospheric composition, and the sensitivity of PE estimates to the choice of canopy resistance values under current and changing climates is demonstrated. The conclusions have practical value for climate change impact studies relating to flood, drought, and water management applications.
\end{abstract}

\section{Introduction}

Evaporation from the land surface is a significant component of a catchment water balance. For hydrological and agricultural water management applications,

Corresponding author address: Victoria A. Bell, Centre for Ecology and Hydrology, Maclean Building, Crowmarsh Gifford OX10 8BB, United Kingdom.

E-mail: vib@ceh.ac.uk the evaporative quantity that affects the water budget directly is actual evaporation (AE) - the water vapor transferred from the land surface to the atmosphere over the catchment area. Actual evaporation is determined in part by the moisture available in the soil and vegetation canopy and in part by the atmospheric demand for water called the potential evaporation (PE). A common definition of PE refers to "the maximum rate of evaporation from a large area covered completely and uniformly by actively growing vegetation with adequate 
moisture at all times" (Brutsaert 2005). However, PE so defined relates to an idealized situation, ignoring the reality of air-water feedbacks and vegetation heterogeneity, and as such can be difficult to quantify.

Evaporation from the stomata of vegetation is often referred to as "transpiration" and the combined evaporation from land and vegetation is sometimes referred to as "evapotranspiration." Similarly, PE from a vegetative surface can also be referred to as "potential evapotranspiration" (PET). The term evapotranspiration was rejected by Penman (1956) and Monteith (1985) as an unnecessary expansion of "evaporation" and use of it is avoided here. In the interests of brevity, the abbreviation PE will be used in subsequent paragraphs to denote potential evaporation from a range of surfaces, but will be qualified by the source if necessary (i.e., open water, vegetation, or soil).

$\mathrm{PE}$ from vegetation is used widely in hydrology in combination with data-driven water balance model estimates of soil moisture to estimate AE and runoff. Such estimation, for example, forms an intrinsic part of rainfallrunoff models used to simulate river flow in flood, drought, and water resource assessments. Estimation of PE is via atmospheric variables such as temperature, wind, and radiation, and is therefore more difficult for catchments without in situ measurements or for applications involving future climate projections. The increasing availability of coupled high-resolution atmospheric and land surface models means that they can be looked to for estimates of both $\mathrm{AE}$ and PE in such situations. However, these estimates are not always immediately relevant to the requirements of hydrologists and engineers working with different models and datasets for water management purposes. Land surface model estimates of AE are more commonly available than PE, but these are dependent on the model's soil moisture, grid size, and input data. The latter do not normally include observations from the extensive hydrometric networks of rainfall and river flow stations available to hydrological and engineering practitioners. These estimates of AE are also dependent on the (often coarse) land-cover datasets used in the atmospheric model configuration, making it difficult for such practitioners to assess the impact of future land-cover and agricultural changes on water resources. Thus, PE is still a valuable and sought-after quantity for offline use (i.e., decoupled from the climate model). It is one step removed from the coarse assumptions made in climate models relating to soil moisture. Using a decoupled PE estimate derived from climate model outputs-for example, assuming a "standard" land cover such as short grassleaves the choice open on what hydrological model and supporting land-cover and hydrometric datasets to employ in water management impact assessments.
Currently, practitioners such as hydrologists who require an estimate of $P E$ from vegetation for use in climateimpact studies use climate model outputs of atmospheric variables as input to one of the many PE estimation schemes available. These schemes vary in complexity and data requirements, ranging from temperature-only methods such as those used by Thornthwaite (1948) and Oudin et al. (2005) to the full Penman-Monteith formulation (Monteith 1965), requiring estimates of air temperature, relative humidity, wind speed, net downward short- and longwave radiation, and aerodynamic and canopy resistance. The more complex PE schemes are often preferred for climate-impact studies as their greater physical basis is likely to be more responsive to climate effects on a range of atmospheric variables. However, these schemes tend to be data intensive and sensitive to the relative accuracy of the driving variables, which can be a disadvantage for long-term climate-impact studies. Recent studies by Ekström et al. (2007) and Kay and Davies (2008) used atmospheric data from a Hadley Centre regional climate model (RCM) to compare PE estimates from a Penman-Monteith formulation with those from a more empirical $\mathrm{PE}$ formulation requiring fewer input variables. In both cases, use of a simpler, empirically based PE formulation led to more realistic PE estimates when compared to observation-based estimates for the control period (1960-90); biases in the RCM driving variables were thought to be the cause of the discrepancy. Evaporation from the stomata of vegetation is influenced by light, temperature, humidity, and carbon dioxide concentration. Projected climate change is linked to elevated levels of $\mathrm{CO}_{2}$, which can impact vegetation growth, distribution, and stomatal closure, and thus modify PE from vegetation through changes to the canopy resistance. Light and low carbon dioxide concentrations lead to stomatal opening, while darkness and high carbon dioxide concentrations lead to stomatal closure. Gedney et al. (2006) suggest that this could result in river flow increasing under projected climate change. These effects are currently absent from most climate-impact analyses undertaken in hydrology, despite their inclusion in many climate models. For example, formulations to estimate PE from climate model output (e.g., used by Fowler et al. 2007, Cameron 2006, Hay et al. 2002, Kay and Davies 2008, Graham et al. 2007, and Andréassian et al. 2004) have neglected the possible effects of increased $\mathrm{CO}_{2}$ concentrations on vegetation dynamics and water use by vegetation. It is common to use climate model output for physical variables such as temperature, wind, and humidity, while setting plant physiological parameters (if included) to literature values. One reason for this is that many PE formulations used for impact assessments either exclude 
terms representing vegetation resistance to the passage of water vapor (e.g., Thornthwaite 1948; Blaney and Criddle 1950; Jensen and Haise 1963) or impose a value suitable only for current climate conditions (e.g., Penman 1948 or Allen et al. 1994). One exception is the full Penman-Monteith formulation, which includes a term for vegetation canopy resistance that can be changed in accordance with the crop type. In the Met Office Rainfall and Evaporation Calculation System (MORECS) implementation (Hough and Jones 1997), this term varies on a monthly basis according to seasonal crop growth.

Here we present a method to estimate PenmanMonteith PE from vegetated surfaces using output from a regional climate model with an embedded land surface scheme. Land surface models-sometimes called soilvegetation-atmosphere transfer (SVAT) schemes-were originally developed to satisfy the requirements of global climate models for estimates of fluxes of heat and water vapor between the land surface and atmosphere. Most of these models estimate surface-air fluxes in one dimension, but can be applied to multiple locations within a domain covering a global or continental area. Overgaard et al. (2006) provide a useful overview of land surface models from a hydrological perspective. They demonstrate how the complexity of these models has progressed from early models that assume the land surface evaporates water at the same rate as a wet surface (e.g., Manabe 1969), to the widely used "big-leaf" models, which include a Penman-Monteith model of evaporation from a grid box associated with a single vegetation type (e.g., Schultz 1998). Later developments resulted in "tiled" models that distinguish between different vegetation types within a grid box but don't allow the various soil-vegetative fluxes to interact (e.g., Avissar and Pielke 1989; Essery et al. 2001). The PE scheme presented here can be configured to both tiled and untiled models. Tiled land surface models are now the more widely used and physically realistic, but the simplicity and computational efficiency of the untiled scheme enables it to be used here to demonstrate the value to impact assessments of incorporating some land surface model developments. The $\mathrm{PE}$ scheme requires minor changes to be made to the land surface component of a climate model in order to provide the necessary outputs to support offline (decoupled from the RCM) hydrological and agricultural climate-impact assessments.

Section 2 presents a simple restructuring of the widely used Penman-Monteith PE scheme in terms of PE from a freely evaporating water surface (i.e., with no "canopy" or vegetative resistance) and two terms representing vegetation canopy resistance to water vapor flux. Application to the Met Office Surface Exchange Scheme (MOSES) I (Cox et al. 1999) and II (Essery et al. 2001) — the untiled and tiled land surface model components, respectively, of the Hadley Centre RCM third climate configuration of the Met Office Unified Model (HadCM3) - is described in section 3. The resulting RCM output variables are used to estimate Penman-Monteith PE under both a current and possible future climate (section 4 ), and the sensitivity of these estimates to the choice of canopy resistance is examined.

\section{Estimating PE from atmospheric data}

The Penman (1948) equation for evaporation over open water (equivalent to a freely evaporating water surface), $\lambda E_{0}\left(\mathrm{~J} \mathrm{~m}^{-2} \mathrm{~s}^{-1}\right.$ or $\left.\mathrm{W} \mathrm{m}^{-2}\right)$, neglecting both ground heat conduction and heat-storage effects, is

$$
\lambda E_{0}=\frac{\Delta R_{n}+\rho c_{p}\left(e_{s}-e\right) / r_{a}}{\Delta+\gamma},
$$

where $\lambda$ is the latent heat of vaporization $\left(\mathrm{J} \mathrm{kg}^{-1}\right), E_{0}$ is the rate of water loss $\left(\mathrm{kg} \mathrm{m}^{-2} \mathrm{~s}^{-1}\right), \Delta$ is the rate of change of saturated vapor pressure with temperature $\left(\mathrm{mb}^{\circ} \mathrm{C}^{-1}\right), R_{n}$ is the net radiation $\left(\mathrm{W} \mathrm{m}^{-2}\right), \rho$ is the nearsurface air density $\left(\mathrm{kg} \mathrm{m}^{-3}\right), c_{p}$ is the specific heat of air at constant pressure $\left(\mathrm{J} \mathrm{kg}^{-1 \circ} \mathrm{C}^{-1}\right), e_{s}$ is the saturation vapor pressure at screen temperature $(\mathrm{mb}), e$ is the screen vapor pressure $(\mathrm{mb}), \gamma$ is the psychro metric constant $\left(\mathrm{mb}^{\circ} \mathrm{C}^{-1}\right)$, and $r_{a}$ is the resistance to vapor transfer in the atmosphere $\left(\mathrm{s} \mathrm{m}^{-1}\right)$. The SI unit conversions are $1 \mathrm{mb}=100 \mathrm{~Pa}$ (or $1 \mathrm{hPa})$ and $x^{\circ} \mathrm{C}=(x+273.16) \mathrm{K}$.

The Penman equation can be adapted to represent $\mathrm{PE}$ from a vegetated surface by replacing the assumed atmospheric resistance to vapor transfer with a combination of atmospheric and canopy resistance to vapor transfer (Monteith 1965). This modification is given by the Penman-Monteith equation, which expresses the latent heat loss from a surface with a vegetative canopy, $\lambda E_{T}\left(\mathrm{~W} \mathrm{~m}{ }^{-2}\right)$, as

$$
\lambda E_{T}=\frac{\Delta R_{n}+\rho c_{p}\left(e_{s}-e\right) / r_{a}}{\Delta+\gamma\left(1+r_{c} / r_{a}\right)},
$$

where $r_{c}$ is the bulk surface (canopy or bare soil) resistance $\left(\mathrm{s} \mathrm{m}^{-1}\right)$. For potential evaporation, $r_{c}$ takes a minimum value (i.e., without soil-moisture stress dependence). Penman-Monteith estimates of PE from a vegetated surface have been evaluated in many environments and are a widely used estimate of PE from land surfaces. Resistance values for different types of vegetation have been derived from field measurements but tend to be vegetation- and site-dependent (Brutsaert 2005), resulting in a certain amount of doubt about their values in a general formula such as Eq. (2). 
The structural similarity between Eq. (1), which estimates evaporation from a freely evaporating water surface, and Eq. (2) for PE from a vegetated surface is apparent. For an untiled land surface model that calculates fluxes for each grid box based on mean "effective" land surface properties, the numerator terms in Eqs. (1) and (2) are identical: there is just one evaporative surface flux for each grid box, which is based on the mean effective parameters for properties such as albedo and aerodynamic resistance. Thus, for untiled land surface models, the Penman-Monteith equation for PE from a vegetated surface (or bare soil), $\lambda E_{T}$, can be rewritten as

$$
\lambda E_{T}=\lambda E_{0}\left[\frac{r_{a}(1+\Delta / \gamma)}{r_{a}(1+\Delta / \gamma)+r_{c}}\right] .
$$

This relation expresses PE from a vegetated surface in terms of evaporation from a freely evaporating water surface $\left(\lambda E_{0}\right)$ and a multiplicative factor containing estimates of bulk aerodynamic and canopy resistance $\left(r_{a}\right.$ and $r_{c}$ ). The simplifying assumption of gridbox mean radiation and resistance parameters in Eqs. (1) and (2) is consistent with the internal assumptions customary in untiled land surface models. Note that for a tiled land surface scheme, these approximations cannot be applied; Eq. (2) can instead be used to estimate PE from a specific vegetated surface.

Evaporation from a freely evaporating water surface is readily available from most climate models as is the bulk aerodynamic resistance term. Canopy resistance can either be assumed to take literature values (e.g., for short grass), or can be obtained from additional climate model output. For the latter, although the user is dependent on the land-cover datasets used in the climate model configuration, this option provides a means to include the effects of climate change upon canopy resistance. These effects are currently absent from most climate-impact analyses undertaken in hydrology, and the scheme outlined in section 3 provides a method of including them.

\section{Worked example using the Hadley Centre regional climate model}

The HadCM3 (Gordon et al. 2000; Pope et al. 2000) is a general circulation model that has previously been shown to have considerable skill at simulating the global climate (e.g., Stott et al. 2000). Here the global climate model is used to provide boundary conditions for a $25-\mathrm{km}$ RCM version of the atmospheric and land surface component of HadCM3, denoted HadRM3 (e.g., Jones et al. 2004), which is set up to simulate climate over Europe in more detail. Both models incorporate the untiled land surface scheme, MOSES I (Cox et al. 1999), and can also be used with the newer tiled version, MOSES II (Essery et al. 2001). These land surface models allow feedbacks from changes in the atmosphere to influence near-surface hydrometeorology, including evaporative fluxes, soil moisture, and runoff. One process in MOSES that is particularly relevant here is its representation of the effect of $\mathrm{CO}_{2}$ concentration on stomatal conductance ( $\mathrm{Cox}$ et al. 1998, 1999). Broadly, the model assumes that the vegetation canopy conductance $g_{c}$ is proportional to canopy photosynthesis and dependent on temperature, solar radiation, and humidity, as well as ambient atmospheric $\mathrm{CO}_{2}$. Increased atmospheric $\mathrm{CO}_{2}$ levels can reduce transpiration through partial stomatal closure. They can also lead to increased plant growth and changes to the leaf area index (LAI), and thus might mitigate the effects of raised $\mathrm{CO}_{2}$ on stomatal closure; however, it has not been possible to quantify these effects here. While the effect of climate change on vegetation and potential evaporation is a complex one, the scheme outlined below provides a method whereby changes to climate model representations of vegetation dynamics can be incorporated in self-standing models used for water management impact assessments.

In terms of atmospheric variables used by MOSES I, PE from a vegetated surface, $\lambda E_{T}$, can be expressed as

$$
\lambda E_{T}=\lambda E_{0}\left[\frac{r_{a}\left(1+\alpha_{1} \lambda / c_{p}\right)}{r_{a}\left(1+\alpha_{1} \lambda / c_{p}\right)+r_{c}}\right],
$$

where $c_{p}$ is the specific heat of air at constant pressure, $\alpha_{1}=\partial q_{\mathrm{sat}} / \partial T, q_{\mathrm{sat}}$ is the saturation specific humidity, and $T$ is the air temperature. This assumes in the conversion from Eq. (3) that $\Delta=(p / \varepsilon)\left(\partial q_{\mathrm{sat}} / \partial T\right)=(p / \varepsilon) \alpha_{1}$ and $1 / \gamma=\varepsilon \lambda / p c_{p}$, where $p$ is air pressure (mb) and $\varepsilon$ is the ratio of molecular weights of water vapor to dry air.

Hence to obtain an estimate of PE for a vegetated surface, $\lambda E_{T}$, requires (i) a value for $\lambda E_{0}$, (ii) a value for the numerator term in Eq. (4), $r_{a}\left(1+\alpha_{1} \lambda / c_{p}\right)$, and (iii) a value for the canopy resistance $r_{c}$. The canopy resistance can be set according to literature values for a chosen standard vegetation, such as short grass, which can vary according to the time of year (e.g., Hough and Jones 1997). The vegetation type used as the standard can be changed in the offline impact assessment to reflect, for example, different land use change scenarios. Alternatively, canopy resistance can adopt the varying values derived from outputs from MOSES that are consistent with its vegetation types for a specific area of application and changing climatic conditions. MOSES does not currently output the value for canopy resistance directly. This has to be calculated from two 
further output variables - canopy conductance $g_{c}\left(\mathrm{~m} \mathrm{~s}^{-1}\right)$ and soil moisture availability $f_{\text {smc }}$ (dimensionless), since $r_{c}=f_{\text {smc }} / g_{c}$. The factor $f_{\text {smc }}$ is required to convert MOSES estimates of $g_{c}$, which are dependent on the model's time-varying "stressed" soil moisture, to the value that would be obtained for saturated conditions (Cox et al. 1998). Note that estimating canopy resistance in this way can be problematic: if $g_{c}$ is zero (e.g., at night when stomata are closed), then $r_{c}$ is infinite. This can have the effect of artificially inflating daily mean values of $r_{c}$.

It is important to note that this method of calculating PE for vegetated surfaces neglects feedbacks incurred through the assumption that evaporation in MOSES occurs at the actual rate rather than the potential rate. At present this is an unavoidable, and likely small, source of error in the PE estimates. An allowance for ground heat flux, as in the MOSES II implementation of the Penman PE formulation, can be included if required, but is not presented here. Note also that PE from vegetated surfaces calculated using Eqs. (3) and (4) can become negative during winter periods when condensation (dew) occurs.

For a tiled land surface model such as MOSES II, the estimates of $\mathrm{PE}$ from a vegetated surface $\lambda E_{T}$ required by hydrologists can be obtained directly from Eq. (2) for each tile type for which estimates of PE are required. The ability to rearrange this equation in such a way as to isolate values of $r_{c}$, which was possible for untiled MOSES I [Eqs. (3) and (4)], is lost. Smith et al. (2006) show how MOSES II can be configured to provide PE estimates by removing the soil-moisture dependence from model AE values (and for a range of land covers, including short grass). However, the results of the experiments undertaken in section 4 using MOSES I, which compare PE estimates arising from the use of constant or variable $r_{c}$ values, may serve to support the use of land surface model PE estimates for different land-cover types in future hydrological or agricultural impact studies.

\section{Assessment of the PE estimation method for U.K. sites}

Estimates of PE derived from 25-km RCM hourly outputs have been examined at three locations across Britain for a one-year period from March 1961. The southernmost location (Amersham) is situated in lowland terrain, while the Scottish location (Cairngorm) is situated in the more mountainous terrain typical of the north and west of Britain. Generally northern Britain is cooler and wetter than the south. The third location in the Midlands (Birmingham) provides a site whose climatology would be expected to lie between the two extremes. Figure 1 provides a location map of the sites together with time series of PE over the year calculated from RCM outputs in different ways. Also included is a historical daily estimate of PE from vegetation using MORECS (Hough and Jones 1997) that employs daily synoptic weather data in the Penman-Monteith equation. PE is a theoretical concept that is not measurable directly and, for U.K. applications, MORECS PE for vegetated surfaces is considered the closest measurementbased estimate of PE there is. Also, there are very few weather stations where all the quantities needed to estimate PE are available concurrently. The absence of a direct measurement of PE for use in validation is somewhat immaterial, as the RCM-driven PE estimates for vegetated surfaces presented in Fig. 1 (labeled "PET" for brevity) are not expected to correspond to the meteorological conditions for any particular year. That is, they derive from a regional climate simulation driven by the global climate model for which the only observed data incorporated into the model are atmospheric concentrations of greenhouse gases and sulfate emissions, and are thus only loosely constrained to reality.

The five different types of PE estimates shown in Fig. 1 are defined below:

1) PET_atmos: PE from land cover, $\lambda E_{T}-\mathrm{a}$ PenmanMonteith estimate using RCM estimates of temperature, humidity, wind speed, and radiation, together with MORECS-specified monthly values of $r_{c}$ for short grass;

2) PET (fixed $r_{c}$ ): PE from land cover, $\lambda E_{T}$ [Eq. (4)], using RCM-MOSES I variables but with MORECSspecified monthly values of $r_{c}$ for short grass;

3) $\operatorname{PET}\left(\operatorname{MOSES} r_{c}\right.$ ): PE from land cover, $\lambda E_{T}$ [Eq. (4)], using RCM-MOSES I variables, including variable $r_{c}$;

4) PE (open water): evaporation from a freely evaporating water surface, $\lambda E_{0}[\mathrm{Eq} .(1)]$; and

5) MORECS: MORECS monthly values of PE based on meteorological observations and short grass land cover.

It is apparent that for all three sites, PE from open water is up to twice as high as PE from vegetated surfaces, particularly during summer. The more northerly Scottish site (Cairngorm) is subject to lower PE than the two southern sites (as expected), but overall, the relative sizes of the different PE estimates are similar for all three locations. Figure 1 indicates that PE estimated using RCM atmospheric variables is generally lower than that from MORECS, employing daily weather observations in line with Ekström et al. (2007) and Kay and Davies (2008), particularly in winter months. Values 
(a) Scotland (Cairngorm)

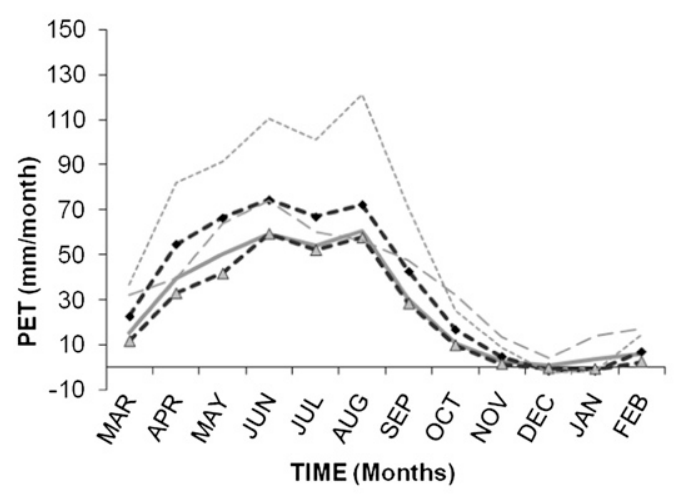

(c) Southeast England (Amersham)

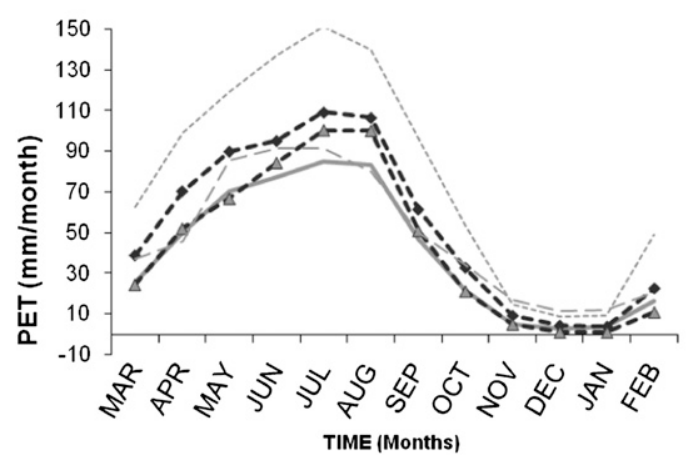

(b) Midlands (Birmingham)

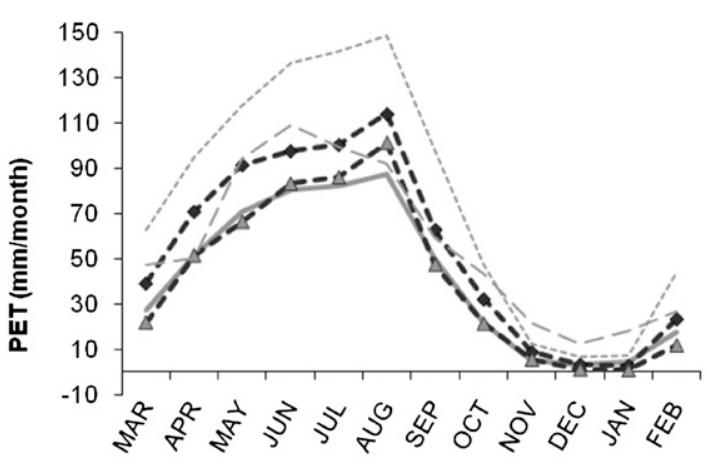

TIME (Months)

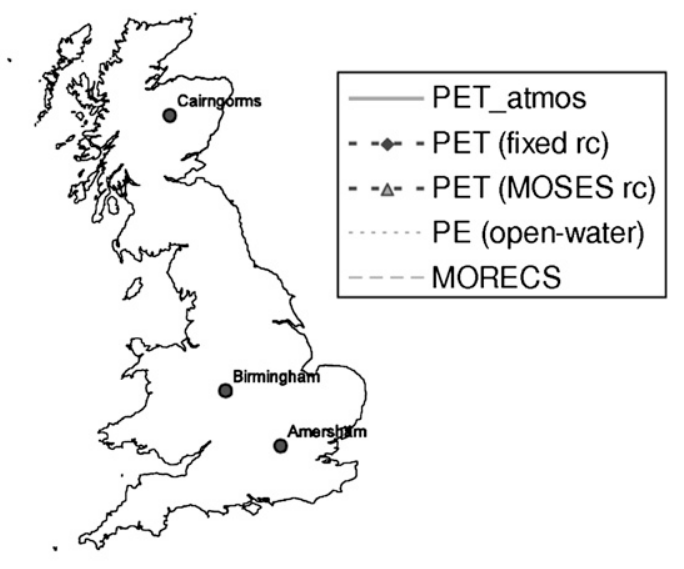

FIG. 1. (a)-(c) Time series of model estimates of potential evaporation for three British sites.

of PE estimated using the new method with a fixed $r_{c}$ for short grass are closest to MORECS monthly estimates, which also assume short grass. Replacing the fixed $r_{c}$ with seasonally varying MOSES values tends to reduce values of PE to be closer to those calculated using RCM meteorological variables. From Eq. (3) it is clear that an increased value of canopy resistance will lead to a decrease in PE from vegetation (further investigation indicates that the variable $r_{c}$ derived from MOSES is indeed larger than the short grass $r_{c}$ used by MORECS). Identification of "true" $\mathrm{PE}$ is problematic: the MORECS values for short grass used here are clearly not representative of the observed land cover, which includes crops and trees.

Maps of the spatial variation of PE for short grass across the United Kingdom are presented in columns (i)-(iii) of Fig. 2 for current climate conditions. Seasonal and annual mean PE totals (1961-90) are shown (i) from 40-km MORECS (observation based) monthly estimates interpolated onto the $25-\mathrm{km}$ RCM grid and from 25-km RCM (MOSES I) data using (ii) fixed $r_{c}$ and (iii)
MOSES variable $r_{c}$. Note that the scale used for the annual mean PE is different from that used for the seasonal mean PE. The RCM-derived estimates are for a current climate simulation driven by HadCM3 as described above; thus maps constructed using these should not be expected to be identical to the observation-based MORECS results. However, it is instructive to compare them in broad terms. Overall, the values of MOSESderived $\mathrm{PE}$ for vegetation obtained using fixed and variable $r_{c}$ are reasonably in line with both the MORECS observation-based estimate and PE values obtained using just RCM atmospheric data (labeled "PET_atmos"). The RCM PE calculated using a fixed $r_{c}$ is generally higher than when a variable $r_{c}$ is used. The greatest difference between the two RCM-derived estimates is during the spring, when RCM PE using a variable $r_{c}$ is quite low compared to MORECS estimates, whereas RCM PE using a fixed short grass $r_{c}$ is generally higher than MORECS.

Employing, in place of fixed literature values, a timevarying $r_{c}$ derived from a land surface model such as 
(i)

MORECS PE 1961-1990
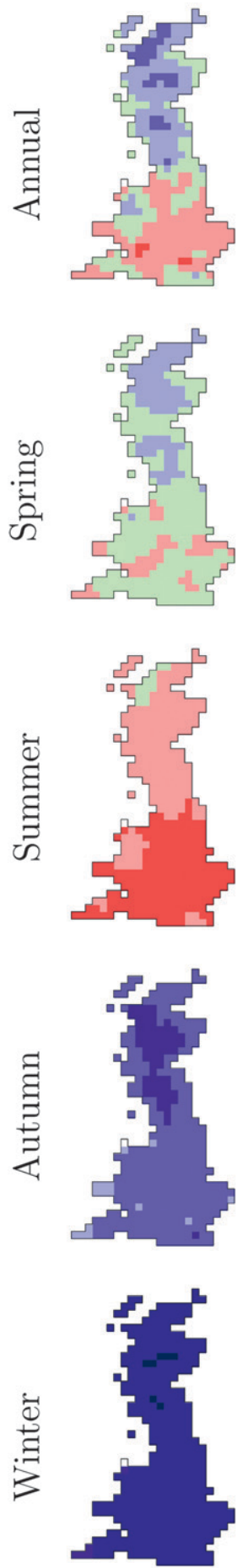

(ii) RCM PE 1961-1990 (fixed $r_{c}$ )
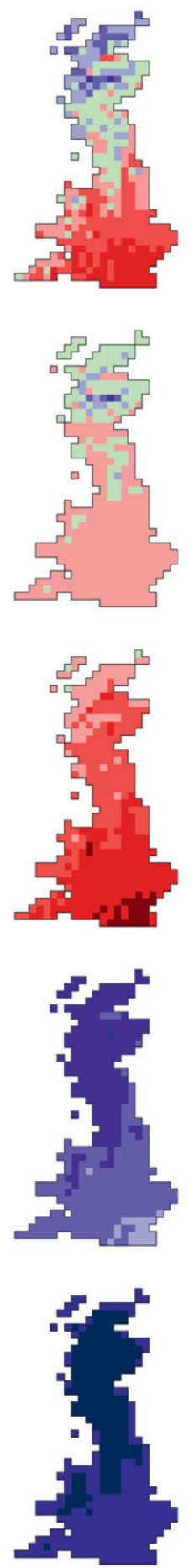

(iii)

$$
\text { RCM PE }
$$$$
\text { 1961-1990 }
$$$$
\text { (MOSES } r_{c} \text { ) }
$$
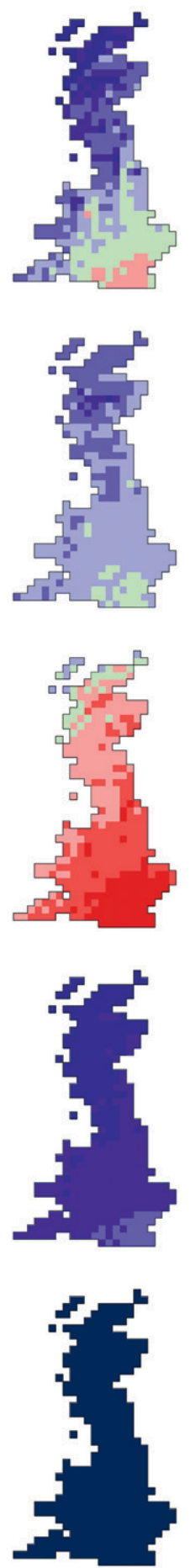

(iv)

RCM PE RCM PE

2070-2099 2070-2099

(fixed $\left.r_{c}\right) \quad\left(\right.$ MOSES $\left.r_{c}\right)$
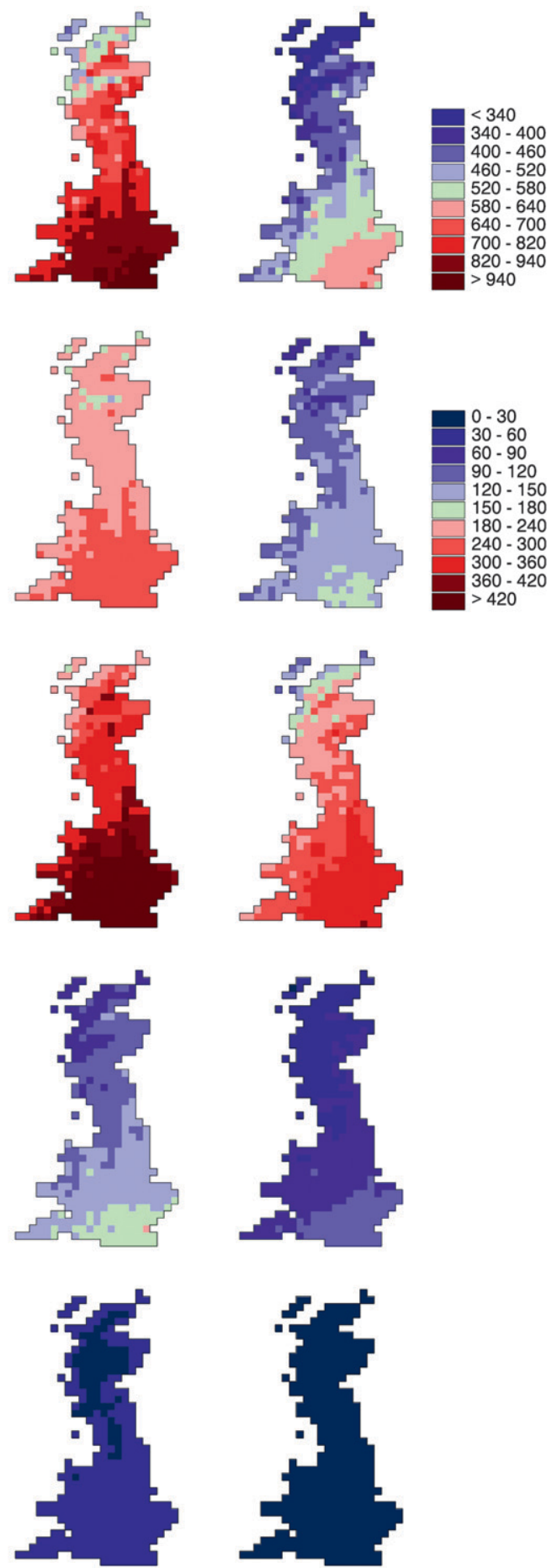

FIG. 2. Model estimates of (top to bottom) the U.K. annual and seasonal mean totals of PE from vegetated surfaces (mm) for current and future time slices. Annual and seasonal totals have separate and different scales. 
MOSES coupled with a climate model provides a means to estimate PE from vegetation consistent with effects of projected future changes in ambient carbon dioxide, temperature, solar radiation, and humidity in the atmosphere. The resulting estimates of $r_{c}$ and PE will be wholly reliant on the climate model configuration, which may or may not include factors such as changes in $\mathrm{CO}_{2}$ levels, LAI, or crop growth. By way of example, the spatial variation of PE from vegetation across the United Kingdom for one possible future climate scenario is shown in columns (iv)-(v) of Fig. 2. The RCM configuration is the same as that used for the present-day $\mathrm{PE}$ maps shown in Fig. 2, columns (ii) and (iii), and is used here to simulate the climate of 2070-99 using boundary conditions from a HadCM3 simulation of this period incorporating atmospheric concentrations of greenhouses gases and sulfate emissions consistent with the Intergovernmental Panel on Climate Change's (IPCC) Special Report on Emissions Scenarios (SRES) A1B emissions scenario (Nakicenovic et al. 2000). Seasonal and annual mean PE totals are presented assuming (iv) literature (MORECS) values of canopy resistance for short grass and (v) MOSES I time-varying $r_{c}$, taking into account elevated $\mathrm{CO}_{2}$ levels, changes in other atmospheric variables, and spatially variable vegetation. U.K. estimates of PE from vegetation assuming a fixed $r_{c}$ are considerably higher than when a time-varying $r_{c}$ is invoked. When the canopy resistance is fixed to literature values for short grass, the annual PE estimates for this future scenario are typically $15 \%-34 \%$ higher than current estimates. However, annual estimates of PE that account for how the vegetation canopy resistance might respond to possible future elevated levels of $\mathrm{CO}_{2}$ are only $3 \%-7 \%$ higher than estimates derived for the current climate.

The basis for the sensitivity of PE estimates to the different values of canopy resistance becomes apparent when estimates of $r_{c}$ based on fixed literature values (e.g., MORECS) and time-varying values from a land surface model (MOSES I) are compared (Fig. 3). The RCM-derived estimates of $r_{c}$ are monthly mean values for a current (1961-90) and future (2070-99) climate simulation driven by HadCM3, and the MORECS estimates are fixed monthly mean literature values based on present-day observations. The difference in the three graphs is immediately apparent, with MOSES future resistance values being up to twice as high as corresponding values for the present day. For the projected future that has increased atmospheric $\mathrm{CO}_{2}$ levels, MOSES estimates of canopy resistance are $\sim 100 \mathrm{~s} \mathrm{~m}^{-1}$ higher than present-day estimates during summer months when evaporation is highest. Higher projected future values of canopy resistance would to some extent counteract increases in PE arising from higher temperatures,

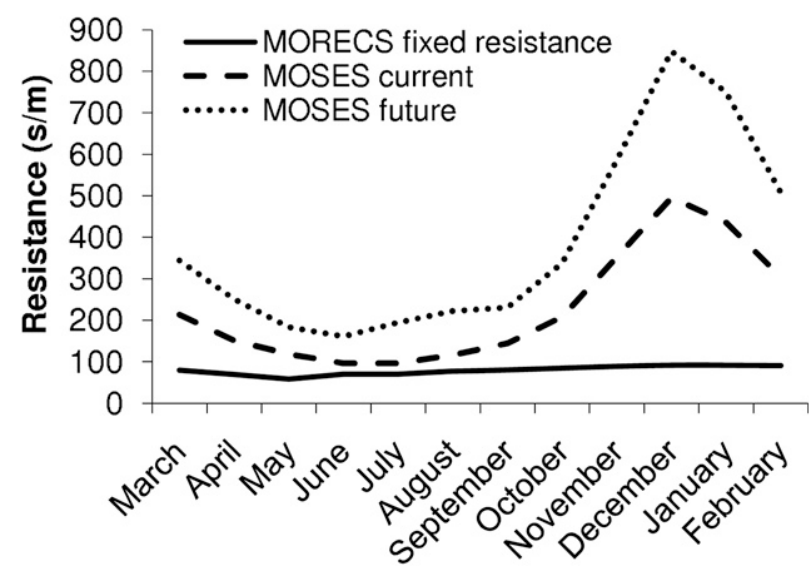

FIG. 3. Estimates of canopy resistance $r_{c}$ for the southeast England site (Amersham).

leading to the future estimates of PE being only $3 \%-7 \%$ higher than estimates derived for the current climate. Figure 3 also compares MOSES and MORECS values of canopy resistance for the present day and indicates that the MOSES values are up to five times higher than MORECS, particularly in the winter season. This difference is due in part to the time step over which they are calculated (although differences in the vegetation type are also a factor). In the land surface model MOSES, the canopy resistance is calculated at an hourly time step and values here are aggregated up to a daily ( $24 \mathrm{~h}$ ) value; in contrast, the literature values used in MORECS calculations are applied at a daily time step only. At night, leaf stomata are typically closed, leading to very low evaporation and a small or zero conductance, $g_{c}$, which can lead to artificially high daily mean estimates of $r_{c}$. In winter months there are fewer hours of daylight, and the effect of including large nighttime values in the 24-h totals is to increase $r_{c}$. However, if 24-h daily totals are rescaled according to the number of daylight hours, MOSES canopy resistance values for the present-day time slice averaged over daylight hours become close to the MORECS literature values, such as those provided by Garrett (1992). Thus, the discrepancy between the present-day MOSES (variable) and MORECS (literature) values is less influential than may be expected, as evaporation at night is very low.

\section{Summary and discussion}

Hydrologists and engineers who require an estimate of $\mathrm{PE}$ for use in water management impact assessments commonly use climate model outputs of atmospheric variables as input to one of the many "offline" PE estimation schemes available. These formulations normally neglect the 
possible effects of increased $\mathrm{CO}_{2}$ concentrations on vegetation dynamics and water use. Many climate models now include terms to represent these processes within their land surface schemes. The PE estimation methods explored here calculate Penman-Monteith PE from vegetated surfaces using outputs from regional climate models that have an embedded land surface scheme. Use of output from a land surface scheme (as opposed to atmospheric variables from the RCM) enables an examination of the sensitivity of offline PE estimates to canopy stomatal resistance values taken from either the literature or the land surface model.

The PE estimation method presented here can be configured to both tiled and untiled models. It requires minor changes to be made to the land surface component of a climate model in order to provide the necessary outputs to support offline (decoupled from the RCM) hydrological and agricultural climate-impact assessments. The simplicity of the untiled land surface scheme has enabled it to be used here to demonstrate the value of incorporating some land surface model developments that have not previously been employed in impact studies for water management. In this case, either fixed literature values of canopy resistance can be used (in line with current practice) or ones that vary spatially and temporarily in line with the projected climatic effects of elevated levels of $\mathrm{CO}_{2}$ on stomatal closure.

Annual estimates of PE that take into account how the canopy resistance might respond to possible future elevated levels of $\mathrm{CO}_{2}$, as well as the more direct effects of climate change on PE, are only 3\%-7\% higher than estimates derived for the current climate scenario. If the effect of increased $\mathrm{CO}_{2}$ on stomata is not taken into account, future levels of $\mathrm{PE}$ from vegetation are estimated to be $15 \%-34 \%$ higher than current estimates. These absolute values of PE changes cannot be taken as predictions as they are based on a single climate scenario. However, their differences demonstrate that it is important to consider the effect of future $\mathrm{CO}_{2}$ emissions on plant physiology in addition to the effect of emissions on physical atmospheric variables such as temperature and humidity. Also, these differences in PE changes provide some guidance on the magnitude of the impact of the effect of future $\mathrm{CO}_{2}$ levels on canopy resistance. Note, however, that only the effect of $\mathrm{CO}_{2}$ on stomatal closure is included in the simulations presented here. There is some evidence that the leaves of plants grown in an atmosphere with a high level of $\mathrm{CO}_{2}$ have reduced numbers of stomata (Woodward 1987), an effect that may reduce simulated future evaporation even further. However, higher levels of $\mathrm{CO}_{2}$ can also cause increased plant growth, which might increase the overall numbers of stomata; the situation is a complex one and it has not been possible to quantify all these effects here.
Hydrologists and engineers, when assessing climate change impacts on flood and drought extremes and water management applications, should consider using PE estimates based on regional climate model outputs and a land surface model. At present, PE estimates from different types of vegetation are not universally available from climate models, and certainly not for the range that practitioners might require in order to assess the impact of land-cover changes on water resources. However, it is relatively straightforward for climate modelers to provide these quantities, as demonstrated in a land surface model by Smith et al. (2006), who discussed how MOSES II had been configured to provide PE estimates for a range of land covers. Alternatively, if climate model estimates of PE remain unavailable, employing a land surface model estimate of canopy resistance consistent with projected climate change effects on carbon dioxide levels in the atmosphere (and stomatal closure) may be important when assessing potential climate change impacts on PE calculated using one of the many offline estimation schemes.

Acknowledgments. This research was supported by the Joint DECC and Defra Integrated Climate ProgrammeDECC/Defra (GA01101) and the CEH Science Programme.

\section{REFERENCES}

Allen, R. G., M. Smith, L. S. Pereira, and A. Perrier, 1994: An update for the calculation of reference evapotranspiration. ICID Bull., 43, 35-92.

Andréassian, V., C. Perrin, and C. Michel, 2004: Impact of imperfect potential evapotranspiration knowledge on the efficiency and parameters of watershed models. J. Hydrol., 286, 19-35.

Avissar, R., and R. A. Pielke, 1989: A parameterization of heterogeneous land surfaces for atmospheric numerical models and its impact on regional meteorology. Mon. Wea. Rev., 117, 2113-2136.

Blaney, H. F., and W. P. Criddle, 1950: Determining water requirements in irrigated areas from climatological and irrigation data. U.S. Department of Agriculture Soil Conservation Service Tech. Paper SCS-TP 96, 44 pp.

Brutsaert, W., 2005: Hydrology: An Introduction. Cambridge University Press, 605 pp.

Cameron, D., 2006: An application of the UKCIP02 climate change scenarios to flood estimation by continuous simulation for a gauged catchment in the northeast of Scotland, UK (with uncertainty). J. Hydrol., 328, 212-226.

Cox, P. M., C. Huntingford, and R. J. Harding, 1998: A canopy conductance and photosynthesis model for use in a GCM land surface scheme. J. Hydrol., 213, 79-94.

— R. A. Betts, C. B. Bunton, R. L. H. Essery, P. R. Rowntree, and J. Smith, 1999: The impact of new land surface physics on the GCM simulation of climate and climate sensitivity. Climate Dyn., 15, 183-203.

Ekström, M., P. D. Jones, H. J. Fowler, G. Lenderink, T. A. Buishand, and D. Conway, 2007: Regional climate model data used within the SWURVE project. 1: Projected changes in seasonal patterns and estimation of PET. Hydrol. Earth Syst. Sci., 11, 1069-1083. 
Essery, R., M. Best, and P. Cox, 2001: MOSES 2.2 technical documentation. Hadley Centre Tech. Note HCTN 30, 30 pp.

Fowler, H. J., C. G. Kilsby, and J. Stunell, 2007: Modelling the impacts of projected future climate change on water resources in north-west England. Hydrol. Earth Syst. Sci., 11, 1115-1126.

Garrett, J. R., 1992: The Atmospheric Boundary Layer. Cambridge University Press, 316 pp.

Gedney, N., P. M. Cox, R. A. Betts, O. Boucher, C. Huntingford, and P. A. Stott, 2006: Detection of a direct carbon dioxide effect in continental river runoff records. Nature, 439, 835-838.

Gordon, C., C. Cooper, C. A. Senior, H. Banks, J. M. Gregory, T. C. Johns, J. F. B. Mitchell, and R. A. Wood, 2000: The simulation of SST, sea ice extents and ocean heat transports in a version of the Hadley Centre coupled model without flux adjustments. Climate Dyn., 16, 147-168.

Graham, L. P., S. Hageman, S. Jaun, and M. Beniston, 2007: On interpreting hydrological change from regional climate models. Climatic Change, 81, 97-122.

Hay, L. E., M. P. Clark, R. L. Wilby, W. J. Gutowski, G. H. Leavesley, Z. Pan, R. W. Arritt, and E. S. Takle, 2002: Use of regional climate model output for hydrologic simulations. J. Hydrometeor., 3, 571-590.

Hough, M. N., and R. J. A. Jones, 1997: The United Kingdom Meteorological Office rainfall and evaporation calculation system: MORECS version 2.0-An overview. Hydrol. Earth Syst. Sci., 1, 227-239.

Jensen, M. E., and H. R. Haise, 1963: Estimating evapotranspiration from solar radiation. J. Irrig. Drain. Eng., 89, 15-41.

Jones, R. G., M. Noguer, D. C. Hassell, D. Hudson, S. S. Wilson, G. J. Jenkins, and J. F. B. Mitchell, 2004: Generating high resolution climate change scenarios using PRECIS. Met Office Hadley Centre, 40 pp.

Kay, A. L., and H. N. Davies, 2008: Calculating potential evaporation from climate model data: A source of uncertainty for hydrological climate change impacts. J. Hydrol., 358, 221-239.

Manabe, S., 1969: Climate and the ocean circulation. 1. The atmospheric circulation and the hydrology of the earth's surface. Mon. Wea. Rev., 97, 739-774.
Monteith, J. L., 1965: Evaporation and environment. Symp. Soc. Exp. Biol., 19, 205-234.

- 1985: Evaporation from land surfaces: Progress in analysis and prediction since 1948. Proc. National Conf. on Advances in Evapotranspiration, Chicago, IL, American Society of Agricultural Engineers, 4-12.

Nakicenovic, N., and Coauthors, 2000: IPCC Special Report on Emissions Scenarios. Cambridge University Press, 599 pp.

Oudin, L., F. Hervieu, C. Michel, C. Perrin, V. Andréassian, F. Anctil, and C. Loumagne, 2005: Which potential evapotranspiration input for a lumped rainfall-runoff model? Part 2-Towards a simple and efficient potential evapotranspiration model for rainfall-runoff modelling. J. Hydrol., 303, 290-306.

Overgaard, J., D. Rosbjerg, and M. B. Butts, 2006: Land-surface modelling in hydrological perspective-A review. Biogeosciences, 3, 229-241.

Penman, H. L., 1948: Natural evaporation from open water, bare soil and grass. Proc. Roy. Soc. London, 193A, 120-148. 1956: Evaporation: An introductory survey. Neth. J. Agric. Sci., 4, 9-29.

Pope, V. D., M. L. Gallani, P. R. Rowntree, and R. A. Stratton, 2000: The impact of new physical parameterizations in the Hadley Centre climate model: HadAM3. Climate Dyn., 16, 123-146.

Schultz, G. A., 1998: Remote sensing in hydrology. J. Hydrol., 100, 239-265.

Smith, R. N. B., E. M. Blyth, J. W. Finch, S. Goodchild, R. L. Hall, and S. Madry, 2006: Soil state and surface hydrology diagnosis based on MOSES in the Met Office Nimrod nowcasting system. Meteor. Appl., 13, 89-109.

Stott, P. A., S. F. B. Tett, G. S. Jones, M. R. Allen, J. F. B. Mitchell, and G. J. Jenkins, 2000: External control of twentieth century temperature by natural and anthropogenic causes. Science, 290, 2133-2137.

Thornthwaite, C. W., 1948: An approach toward a rational classification of climate. Amer. Geogr. Rev., 38, 55-94.

Woodward, F. I., 1987: Stomatal numbers are sensitive to increases in $\mathrm{CO}_{2}$ from pre-industrial levels. Nature, 327, 617-618. 